\title{
The Usability of Web Accessibility Guidelines: An Approach for Evaluation
}

\author{
Maria Kapsi, Evangelos Vlachogiannis, Jenny Darzentas, Thomas Spyrou \\ University of the Aegean, Department of Product and Systems Design Engineering \\ Hermoupolis, Syros, GR84100, Greece \\ \{dpsd01022, evlach, jennyd, tsp\}@aegean.gr
}

\begin{abstract}
This paper aims at contributing to the evaluation of web accessibility and thus promoting design for all, considering the design process as an iterative process containing evaluation as a fundamental component. More specifically, the paper: 1) rethinks Web Accessibility Evaluation notion and its abstract requirements, 2) investigates the usability of W3C Web Content Accessibility Guidelines (WCAG 1.0 and WCAG 2.0), and 3) proposes an approach for an evaluation of the usability of accessibility guidelines.
\end{abstract}

Keywords: accessibility, WCAG, W3C, usability, evaluation

\section{Introduction}

For the last decade, the research community has devoted much effort to developing guidelines and procedures for allowing web developers to make web products accessible to people with special needs. These are also operable by the upcoming new devices, technologies and in emerging contexts of use. The accessibility focuses on application characteristics that support universal access, regardless of the type of user or technology (Matera et al, 2006).

Accessibility has been promoted and enforced by countries and organizations through policies and legislations. Countries on both sides of the Atlantic have included eAccessibility into their laws. The most well known are Section $508^{1}$ in USA and Disability Discrimination Act (DDA) 1995 (updated in 2005) in UK. The i2010², the EU policy framework for the Information Society and Media, promotes, with the tools available to the Commission, a European Information Society for all citizens. Actions implemented under this priority of i2010 aim to ensure that the benefits of the information society can be enjoyed by everyone (eAccessibility) and encourage provision of better public services (eGovernment, eHealth).

The goal of this paper is to contribute to the field of web accessibility by concentrating on evaluation of accessibility which is seen as fundamental component of accessible web design. Legislation has made this kind of evaluation even more central to web accessibility as it is required for the conformance of web sites to the

\footnotetext{
${ }^{1} \mathrm{http}: / /$ www.section508.gov/

${ }^{2} \mathrm{http} / / /$ ec.europa.eu/information_society/eeurope/i2010/index_en.htm
} 
corresponding laws. That is, without evaluations of web sites to see whether they pass certain tests and checks and comply with the guidelines, these laws cannot be enforced. Laws promoting accessibility are often linked with well established de-facto standards, like Web Content Accessibility Guidelines (WCAG) recommended by the Web Accessibility Initiative (WAI) of World Wide Web Consortium (W3C).

This paper begins with a presentation of the state of the art in the field of web accessibility evaluation. Next the authors attempt to distinguish the notion of web accessibility from usability so as to contribute to the clarification of web accessibility. The usability of accessibility guidelines is examined; and more specifically WCAG 2.0 is compared with WCAG 1.0 , in terms of their respective usability by applying them to a web page. Finally, this paper proposes an approach for the evaluation of the usability of web accessibility guidelines. The approach is sufficiently abstract so that it can serve the design of any set of web accessibility guidelines. This research examines guidelines from an evaluator perspective rather than a web site creator perspective

\section{Background}

The WCAG guidelines were first formulated in 1997, (WCAG 1.0) and offered alongside the recommendations, techniques to remedy problem situations. However, these techniques were HTML centric and generally based upon technologies of a now previous decade and already in 2001 work began upon a new set of guidelines that resolved to be less technology dependent (Caldwell et al, 2006).

According to WCAG 2.0: 1) the Information and user interface components must be presentable to users in ways they can perceive, 2) the user interface components and navigation must be operable, 3) the information and the operation of user interface must be understandable and 4) the content must be robust enough that it can be interpreted reliably by a wide variety of user agents, including assistive technologies.

The seven-year (since 1st working public draft in 2001) effort to reach consensus on WCAG 2.0 produced guidelines that are fairly different from WCAG 1.0, nevertheless they still present weaknesses. According to several researchers in the field (see, for instance, Brewer, 2005 and Moss, 2006), they are presented at a very abstract level using general and vague terms, they are characterized by low usability level since they use even more obscure terminology than WCAG 1.0 and they require a great deal of explanation to become comprehensible.

Until very recently, web designers and those commissioning web sites, were faced with a dilemma regarding which of the versions of WCAG they should use since the first one is well out of date but stable, while the second one up to date but generating much doubt because of the difficulty of applying the guidelines due to their perceived lack of usability.

A methodology, which has already been adopted by some organizations, for evaluation of conformance with the WCAG 1.0 is the Unified Web Evaluation Methodology - UWEM. The UWEM is the result of the combined efforts of three European projects that make up the Web Accessibility Benchmarking Cluster - the 
WAB Cluster. The methodology supports both expert and automated evaluation while is suitable for detailed evaluation of single web pages, entire sites and sets of sites. The UWEM provides also recommendations sampling methods and reporting options. The goals of the evaluation diversify: 1) acquire a quality label, 2) get feedback on problematic issues to be improved, or 3) comparative evaluation of multiple sites so as to get information about websites that are below average regarding web accessibility (monitoring) or identify good practice examples (Nietzio et al, 2008) Some changes are required for the maintenance of UWEM, especially regarding WCAG 2.0.

Reporting the results of the evaluation is a critical task since any redesign is based upon the report. It becomes even more critical in cases where there is more than one evaluator. For helping with the report, theUWEM suggests, without being restrictive, the use of the Evaluation and Report Language (EARL) (McCathieNevile and AbouZahra, 2007). EARL is designed to describe the evaluation results in a machine readable (XML/RDF) format. Using EARL facilitates the comparison of test results; and allows the aggregation of test results. The main components of the EARL report structure are 1) Who (or which tool) runs a test, 2) The resource tested, 3) The result(s) of the test and 4) The tested criterion(-a). EARL is used for the reporting of this work's case study.

\section{$3 \quad$ Rethinking Web Accessibility - Accessibility vs Usability}

Investigating the literature on the history of web accessibility, reveals that there is still no clear distinction between the former notion and the well established notion of usability. According to several approaches (e.g. Thatcher et al., 2002; Henry, 2007), web accessibility is considered as a special case of usability. These approaches basically rely on the ISO 9241-11 (International Organization for Standardization) definition of usability. The definition includes: a) the PwD (People with Disabilities) as prescribed users and b) a plethora of conditions, including assistive technologies as a specific context of use. Based on such a definition, if a user interface stands as accessible then this entails that it is usable as well (see Fig. 1).

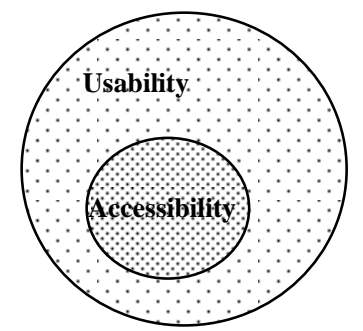

Fig. 1. Usability Vs Accessibility from an ISO perspective.

However, in real life this does not hold, as several "accessible" designs seem not be necessarily usable. For instance, in the case of a non-descriptive alternative text 
being used for an image, the design would probably pass an automatic accessibility evaluation successfully (WCAG 1.0), this does not mean that such a design would be usable.

A way to examine the relation between usability and accessibility could be a kind of classification of user interface problems (Henry, 2007):

- Usability problems: face all users equivalently regardless of their abilities. In other words, someone with a disability is not at disadvantage on usability issues, when compared with a non-disabled user

- Accessibility Problems: This kind of problems prevents PwD from accessing a web page. This means that a person with disabilities is at disadvantage compared with a non-disabled person

Other researchers (e.g. RNIB, 2008) try to distinguish accessibility from usability as being to completely separate notions (see Fig. 2).

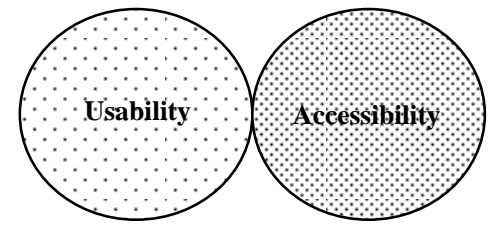

Fig. 2. Usability Vs Accessibility: Separate notions?

A possible reason of confusion regarding aforementioned notions may be due to the fact that accessibility was introduced for the first time as a design requirement by the U.S.A. Section 508 - Rehabilitation Act. Here accessibility was identified with a series of guidelines and, as a consequence, designers focus on the technical aspects of the notion. This means that the wider definition, which includes the viewpoint of usability, was seen as something apart and separate from accessibility.

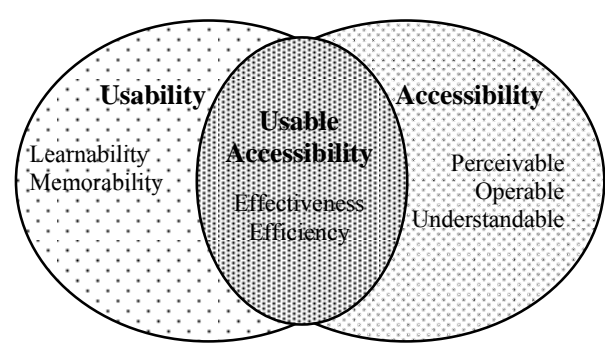

Fig. 3. Usable Accessibility: The intersection.

Based on Thatcher et al. (Thatcher et al., 2002), who defined the notion of usability based on Nielsen's principles (Nielsen, 1995) and the technical viewpoint of accessibility based on the principles of WCAG 2.0, it seems that the usability viewpoint of accessibility, what is termed as Usable Accessibility, can be identified through the correspondences of the usability principles to the accessibility principles. This correspondence is actually the intersection of the two notions. So, it can be seen 
in Fig.3 that some characteristics are pure usability or accessibility ones and some other belong to the grey area of the intersection.

\section{A preliminary Comparative Evaluation of WCAG 1.0 and 2.0}

Aiming at investigating the usability of both WCAG 1.0 and WCAG 2.0, a comparative study of a single web page took place as part of a final year project at the Department of Product and Systems Design Eng. (DPSD) - University of the Aegean. The evaluators were final year students, who seemed a good choice in order to represent a novice average reader of WCAG. The actual subject of evaluation was the home page of the DPSD web site (http://www.syros.aegean.gr/gr.aspx). Of course such a restricted evaluation is not capable of raising all the issues as it does not even cover all the guidelines; however it is capable of providing a first picture and provide guidance for further work on the usability of the guidelines. More details can be found in (Kapsi et al, 2009) which deals with the evaluation reports.

The perspective of this paper is to focus on the usability issues faced while using the WCAG 2.0, especially in comparison with the use of WCAG 1.0. It should be mentioned that such conclusions are drawn mostly from the experience of a novice web accessibility evaluator who firstly came in contact with WCAG 1.0 and then with WCAG 2.0.

The first contact with WCAG 2.0 causes a very negative perception for their usability as the document structure and organization seems difficult to understand. It is time consuming to get used to these and thus difficult to practice efficiently When the WCAG reader is on the level of principles or even the level of guidelines it seems difficult to ground the meaning of each of them. However, this becomes much clearer when the reader reach the techniques level, something that does not happen with WCAG 1.0 .

However, it could be claimed that having studied WCAG 1.0 before, probably made the readers' somewhat biased to the structure of WCAG 1.0 and consequently made understanding the WCAG 2.0 structure much more difficult. For instance, the reader tends to look for a correspondence between principles / guidelines and Checkpoints / Success Criteria but it finally makes more sense to correspond checkpoints with WCAG 2.0 techniques, which is not also absolutely correct. It would be very interesting to investigate the opinion of another set of users who do not come through WCAG 1.0 before working with WCAG 2.0 .

On the other hand, WCAG 2.0 terms and notions seemed more understandable as the users met them in the previous version as well. WCAG 2.0 techniques seem really useful to effectively guide the designer to the conformance with the success criteria. However, some of the success criteria seem rather wordy requiring more time to understand and apply. The techniques give precise instructions and have none of the generalities that are found in WCAG 1.0. Finally, it is probably unavoidable but also disappointing that both WCAG 1.0 and 2.0 versions make extensive use of their own terminology and thus use of "jargon" makes comprehension for a non-expert user very difficult. 


\section{An Approach for a Usability Evaluation of Web Accessibility Guidelines}

From the discussion in the last section, it appears that the test of the WCAG create several usability problems that may prevent, especially novice designers, from applying them and consequently pose barriers to the accessibility of the web. In this section the authors propose an approach for evaluating the usability of guidelines, in particular those relating to accessibility. Such an approach could be used in order to evaluate the current version of WCAG or other sets of guidelines or even to support the design of future guidelines.

The proposed evaluation process is based on Demarteau's theoretical framework of evaluation processes (Demarteau, 2002) in the field of program evaluation. According to Demarteau evaluation consists of three components: "the process of information collection; the value judgment that is the product of this process; and finally the use of the value judgment in the decision making leading to action. These three components also cover three evaluation issues: to know, judge and decide."

Based on the Demarteau framework, the work here specifies as "process of information collection" the collection of data regarding guidelines usability issues. In particular, in this evaluation phase, all the usability problems that concern accessibility guidelines are collected as the last step leading to the decision making for the improvement of the problematic situation.

\begin{tabular}{lll} 
Guidelines Usability Evaluation Process & \\
\hline $\begin{array}{l}\text { Collection of data regarding } \\
\text { guidelines usability }\end{array}$ & $\begin{array}{l}\text { Critique of usability } \\
\text { issues }\end{array}$ & Decision making \\
$\begin{array}{l}\text { (Prospective guidelines } \\
\text { usability issues) }\end{array}$ & $\begin{array}{l}\text { (Classification / } \\
\text { association of problems } \\
\text { and overall conclusions) }\end{array}$ & $\begin{array}{l}\text { (Suggestions for } \\
\text { improvement) }\end{array}$ \\
\hline
\end{tabular}

Fig. 4. : Evaluating the Usability of Guidelines.

In order to support the evaluator in data collection regarding usability issues of the guidelines, the basic principles of the heuristic evaluation usability method (Nielsen, 1994), an inspection evaluation approach, have been recruited. Nielsen describes heuristic evaluation (Nielsen and Molich, 1990; Nielsen 1994) as a usability engineering method for finding the usability problems in a user interface design so that they can be attended to as part of an iterative design process. The method involves having a small set of evaluators examine the interface and judge its compliance with recognized usability principles (the "heuristics"). In particularly, for the evaluation of the user interface design Nielsen came up with ten general principles ${ }^{3}$ including: 1) visibility of system status, 2) match between system and the real world, 3) user control and freedom, 4) consistency and standards, 5) error prevention 6) recognition rather than recall, 7) flexibility and efficiency of use, 8)

\footnotetext{
${ }^{3}$ http://www.useit.com/papers/heuristic/heuristic_list.html
} 
aesthetic and minimalist design, 9) Help users recognize, diagnose, and recover from errors and 10) Help and documentation.

Based on the preliminary evaluation of the WCAG (Kapsi et al, 2009) and authors' experience, it appears that a set of guidelines can be examined from three different perspectives: the structure, the content and the interface (for the case of WCAG the interface being the interface into a hypertext document). Consequently, from such a point of view, the usability evaluation of a set of guidelines involves their examination from all these three perspectives. For the evaluation of each perspective, the authors have adopted and adapted Nielsen's principles. Specifically for the interface perspective the ten principles apply as they are and thus they are not discussed further. The adapted heuristics for the structure are analyzed in Table 2

Table 1. Structure Perspective Heuristics.

\begin{tabular}{|l|l|}
\hline \multicolumn{2}{|c|}{ Structure Perspective Heuristics } \\
\hline $\begin{array}{l}\text { Transparency / } \\
\text { Visibility }\end{array}$ & $\begin{array}{l}\text { The abstraction levels of guidelines should be transparently organized. } \\
\text { Specifically, starting from the higher level of organization the meaning and } \\
\text { the content of the guideline should be clear and unambiguous for the reader } \\
\text { to understand. Additionally, the passage between the levels of abstractions } \\
\text { should be smooth }\end{array}$ \\
\hline Effectiveness & $\begin{array}{l}\text { The structure of the guidelines should increase the productivity of the reader } \\
\text { and not only distinguishing between the sections. This means that logical } \\
\text { organization of the guidelines should be helpful. }\end{array}$ \\
\hline Easy to remember & $\begin{array}{l}\text { The structure should be easy to remember, so that an occasional reader could } \\
\text { return after a period and still be able to use it effectively }\end{array}$ \\
\hline Documentation & $\begin{array}{l}\text { Documentation should be provided in case the user needs further help } \\
\text { understanding (e.g. texts for deeper understanding of the structure) }\end{array}$ \\
\hline
\end{tabular}

The adapted heuristics for the content perspective are analyzed in Table 2.

Table 2. Content Perspective Heuristics.

\begin{tabular}{|l|l|}
\hline \multicolumn{2}{|c|}{ Content Perspective Heuristics } \\
\hline Error prevention & $\begin{array}{l}\text { The guidelines should report examples to be avoided, bad practices and } \\
\text { promote error notification before these happen. }\end{array}$ \\
\hline Severity & $\begin{array}{l}\text { The texts should be short, simple and targeted. The terminology should be } \\
\text { simple. }\end{array}$ \\
\hline Consistent & $\begin{array}{l}\text { Avoid using jargon language. When special terminology is unavoidable, } \\
\text { provide special glossary and use terminology consistently }\end{array}$ \\
\hline Application practices & $\begin{array}{l}\text { The reader should meet real world examples in order to ensure the passage } \\
\text { of the theoretical guideline to the application in real world }\end{array}$ \\
\hline Help & $\begin{array}{l}\text { The guidelines need to be understandable without using requiring help. } \\
\text { However, guidelines documents should provide help in order to support the } \\
\text { reader in case there are misunderstandings. The help need to be short, } \\
\text { accessible through search facilities, provide step by step guidance and be } \\
\text { focused to the desired result for the reader }\end{array}$ \\
\hline
\end{tabular}




\section{Conclusions and Further Work}

Considering that accessibility guidelines create usability issues that prevent the promotion of web accessibility, this paper presented an approach for guiding the usability evaluation of accessibility guidelines. More specifically, this work tried to provide the fundamental components that need to be taken into account during the design of accessibility guidelines so as to be usable. This approach is studied as a design process itself, in which there can be identified correlated phases. The proposed approach provides a model so that it can support the evaluator in order to go through with each phases and optimize alternatives.

This paper presented a viewpoint of the notion of web accessibility by attempting to place web accessibility's place on the research map by comparing it with the well established field of usability, and at the same time clarifying the relation between the usability and accessibility. The need to attend to the usability of accessibility guidelines was discussed and in particular WCAG usability was briefly examined and came up with several conclusions. These conclusions were fed back to an emerging approach for a usability evaluation of any set of accessibility guidelines. Such an approach can be used for the evaluation of existing guidelines, probably not restricted in the accessibility field, but could also be used themselves as guidelines for the design of future guidelines.

Of course, from such a preliminary evaluation of WCAG the conclusions cannot be that generalisable. The approach would need to be improved and evaluated. As the proposed model is based on heuristic evaluation, it seems important to involve more designers and evaluators for better results. In particular, many evaluators should be involved on the same web accessibility guidelines' set so as to take into account more and diverse aspects of usability issues. In this way many probable usability issues may be dealt with before delivering to users and in this way it could be arisen, indirectly, some failures of the model. Nevertheless, this work has provided a viewpoint which can be used for further research. Using our proposed evaluation process, based on the heuristics and the diversion between content, structure and interface, it may be possible to see for instance the structure and content are usable but the interface is difficult.

Finally, as the accessibility guidelines become more and more complex primarily due to technology advances, it comes apparent the requirement for designing and developing accessibility guidelines support tools that could be able to communicate the guidelines more effectively than the guidelines themselves probably through the enhancement of the "interface perspective". The proposed approach here could play the role of design specifications for such a tool.

\section{References}

1. Brewer, J., 2005. How People with Disabilities Use the Web. Working-Group Internal Draft, 5 May 2005 
2. Caldwell, B., Chisholm, W., Slatin, J., Vanderheiden, G., Web Content Accessibility Guidelines 2.0. W3C Working Draft 27 April 2006 (http://www.w3.org/TR/2006/WDWCAG20-20060427)

3. Clark, J. 2006. To Hell with WCAG 2. In "A List Apart Magazine" (ISSN: 1534-0295). (accessed, 29/10/08) http://www.alistapart.com/articles/tohellwithwcag2

4. Demarteau, M. (2002). A Theoretical Framework and Grid for Analysis of Programmeevaluation Practices Evaluation 8: 454-473

5. Henry, Shawn Lawton. Just Ask: Integrating Accessibility Throughout Design. Madison, WI: ET\Lawton, 2007. ISBN 978-1430319528 www.uiAccess.com/JustAsk/

6. Henry, S. L., 2007, Just Ask: Integrating Accessibility Throughout Design. Madison, WI: ET $\backslash$ Lawton, www.uiAccess.com/justask/

7. Kapsi M., Vlachogiannis, E., Darzentas J S, Spyrou T.. A preliminary feedback for the WCAG 2.0 - WCAG 1.0 Vs WCAG 2.0 evaluation study. Submitted as short paper for : PETRA 2009 Conference

8. McCathieNevile, C., Abou-Zahra, S. (2007): Evaluation and report language (EARL) 1.0. Schema. W3C Working Draft 23 March 2007. Available at http://www.w3.org/TR/2007/WD-EARL10-Schema-20070323

9. Moss, T. 2006. WCAG 2.0: The new W3C accessibility guidelines evaluated. Webcredible web accessibility article,. September 2006. (accessed, 29/10/08) http://www.webcredible.co.uk/user-friendly-resources/web-accessibility/wcag-guidelines20.shtml.

10. Nielsen Jakob, Usability Engineering, Morgan Kaufmann Publishers Inc., San Francisco, CA, 1995

11. Nielsen, J. (1994). Heuristic evaluation. In Nielsen, J., and Mack, R.L. (Eds.), Usability Inspection Methods. John Wiley \& Sons, New York, NY.

12. Nielsen, J., and Molich, R. (1990). Heuristic evaluation of user interfaces, Proc. ACM CHI'90 Conf. (Seattle, WA, 1-5 April), 249-256.

13. Nietzio A, Strobbe C, Velleman E, 2008. The Unified Web Evaluation Methodology (UWEM) 1.2 for WCAG 1.0. In: Miesenberger K et al. (eds). Proceedings of the 11th International Conference ICCHP 2008 (Linz, Austria, July 2008), LNCS 5105, pp. 394-401. Berlin-Heidelberg: Springer-Verlag. DOI: 10.1007/978-3-540-70540-6 57

14. RNIB, 2008, Accessibility, usability and inclusive design - Software Access Centre, RNIB, http://www.rnib.org.uk/xpedio/groups/public/documents/PublicWebsite/public_sacusability. hesp

15. Thatcher J, Waddell C, Henry S, Swierenga S, Urban M, Burks M, Regan B, Bohman P (2002) Constructing accessible web sites. Glasshaus, Birmingham, UK

16. Velleman, E., Velasco, C. A., Snaprud, M., 2007. D-WAB4 Unified Web Evaluation Methodology (UWEM $1.2 \quad 10$ Core) http://www.wabcluster.org/uwem1_2/UWEM_1_2_CORE.pdf 